\section{PSQ-070 SAFETY STRATEGIES TO IMPROVE DRUG LABELLING IN OPERATING ROOMS}

A Melgarejo-Ortuño*, A Ribed-Sánchez, ML Bermejo-Albares, A García-García, Á GiménezManzorro, MÁ Amor-García, Á Narrillos-Moraza, S García-Sánchez, F García-Moreno, A Herranz-Alonso, M Sanjurjo-Saez. 'Hospital General Universitario Gregorio Marañon, Pharmacy, Madrid, Spain; ${ }^{2}$ Hospital General Universitario Gregorio Marañon, Anaesthesia, Madrid, Spain; ${ }^{3}$ Hospital General Universitario Gregorio Marañon, Nursing, Madrid, Spain

\subsection{6/ejhpharm-2020-eahpconf.387}

Background and importance Operating rooms (OR) are an area with a significant proportion of high risk, high alert medications. A new law was passed in 2016 in Spain with the objective of improving safety regarding drug identification in the OR and describing the correct labelling of reconstituted medication.

Aim and objectives The aim of this study was to describe the actions developed to adapt our environment to the new legislation and to analyse intravenous drug labelling in daily clinical practice.

Material and methods A committee was created composed by anaesthetists, surgeons, and nursing and pharmacy departments. Seven brainstorming sessions were carried out to apply the new law to our OR in clinical practice. A transversal observational study was conducted over 2 days in a tertiary hospital in October 2019. Variables were collected by nurses from reconstituted medication in bags and syringes.

Results It was decided that the following variables should be described in our drug labels and were consequently collected for the study: patient identification (name and ID), drug, dose or concentration, total volume and administration route. For the syringes, we collected drug name and dose.

We decided that autofill ID patient labels and white labels to identify drugs should be pre-printed before the operation. In addition, pre-printed syringe labels were purchased complying with the colour code used in the international system. The information was disseminated to the departments in September 2019.

The total number of bags analysed was 91, and 55 (60.4\%) were correctly identified according to all standards: 66 (72.53\%) with patient information, 88 (96.7\%) with drug identification, 81 (89\%) with dose or concentration, 77 $(84.6 \%)$ with total volume and $72(79.1 \%)$ with administration route. The median total number of bags per patient was $2.7 \pm 0.8$. The total number of syringes analysed was 113 , and $60(53.1 \%)$ were correctly identified: 93 (82.3\%) with the drug identification label and $60(53.1 \%)$ with dose identification. The median total number of syringes per patient was $2.5 \pm 1$.

Conclusion and relevance Reconstituted medication labelling in our OR adequately followed the standards but there is room for improvement. New measures will be discussed in training sessions on the importance of patient identification, administration route and syringe doses, and new pre-printed syringe labels will be purchased. A new study will be conducted in November 2019.

\section{REFERENCES AND/OR ACKNOWLEDGEMENTS}

No conflict of interest.

\section{PSQ-071 AN ADVERSE DRUG REACTION IN A PAEDIATRIC PATIENT WITH DRAVET SYNDROME: CANNABIDIOL AND VALPROATE DRUG-DRUG INTERACTION}

${ }^{1} \mathrm{~GB}$ Ortenzi ${ }^{*},{ }^{2} \mathrm{E}$ Cesaroni, ${ }^{3} \mathrm{MA}$ Berardi, ${ }^{1} \mathrm{AMF}$ Garzone, ${ }^{1} \mathrm{E}$ Andresciani, ${ }^{3} \mathrm{C}$ Polidori, ${ }^{1}$ A Pompilio. ${ }^{1}$ AO Ospedali Riunti Di Ancona, Sod Farmacia, Ancona, Italy; ${ }^{2}$ AO Ospedali Riuniti Ancona, Sod Neuropsichiatria Infantile, Ancona, Italy; ${ }^{3}$ Università Degli Studi Di Camerino, Scuola Di Scienze Del Farmaco E Dei Prodotti Della Salute' Facoltà Di Farmacia, Camerino, Italy

\subsection{6/ejhpharm-2020-eahpconf.388}

Background and importance Cannabis based therapies have been used to treat epilepsy for millennia, but in the past few years several studies have led to the marketing in Europe of a drug based on cannabidiol with an indication for Lennox-Gastaut and Dravet syndrome, authorised in Italy on compassionate use.

Aim and objectives The aim of this study was to describe an adverse drug reaction (ADR) in a patient with Dravet syndrome treated with cannabidiol oral solution.

Material and methods Periodic reports required by the compassionate use protocol and pharmacovigilance activity were used to collect the data.

Results The patient fulfilled all eligibility criteria: female patient born in January 2001, body weight $60 \mathrm{~kg}$, diagnosed with Dravet syndrome and inadequate seizure control with standard therapy (valproic acid (VPA) $600 \mathrm{mg} /$ day, clobazam $20 \mathrm{mg} /$ day and stiripentol $2000 \mathrm{mg} /$ day).

In January 2019, cannabidiol oral solution $100 \mathrm{mg} / \mathrm{mL}$ was added to the therapy, after a favourable opinion by the ethics committee and informed consent was obtained. The following dosing schedule was used: $5 \mathrm{mg} / \mathrm{kg} /$ day for 7 days and 10 $\mathrm{mg} / \mathrm{kg} /$ day for 7 days, and a maintenance dose of $15 \mathrm{mg} / \mathrm{kg} /$ day.

In February 2019, an adverse reaction was reported: increased hepatic enzymes AST 151U/L (0-40), ALT $45 \mathrm{U} / \mathrm{L}$ (0-40), blood levels of VPA $115.2 \mu \mathrm{g} / \mathrm{mL} \quad(50-100)$ and decreased platelet count $126 \times 10^{3} / \mathrm{mmc}(150-400)$.

In March 2019, hepatic enzyme levels decreased (AST 78 $\mathrm{U} / \mathrm{L}$, ALT $24 \mathrm{U} / \mathrm{L})$ but platelet count decreased further to $98 \times 10^{3} / \mathrm{mmc}(150-400)$ and blood levels of VPA increased (129.7 $\mu \mathrm{g} / \mathrm{mL})$. The physician considered reducing the daily dose of VPA to $10 \mathrm{mg} / \mathrm{kg} /$ day. In June 2019, platelet count was $187 \times 10^{3} / \mathrm{mmc}(150-400)$ and VPA $101.8 \mu \mathrm{g} / \mathrm{mL} \quad(50-$ 100). The Naranjo algorithm, with a result of 7 , determined the event related to cannabidiol/valproic acid as 'probable'.

Conclusion and relevance The interaction between VPA and CBD has already been reported in the literature with strong evidence in favour of hepatocellular toxicity but there is no evidence regarding the modification to platelet count. The strict management of the drug was critical to minimise the collateral effects. Cannabidiol therapy did not produce detectable effects on the management of seizures, but the therapy was not suspended thanks to a detectable increase in the patient's cognitive and social capacities.

\section{REFERENCES AND/OR ACKNOWLEDGEMENTS}

Www.micromedexsolutions.com access on 19/11/2019

No conflict of interest. 